\title{
Serviço Social: \\ um enfant terrible na institucionalidade burguesa?
}

\section{Social work: an enfant terrible in the bourgeois institutionality?}

\author{
Potyara A. P. Pereira \\ Professora titular e emérita do Departamento de Serviço Social da Universidade de Brasília - UnB, Brasil. \\ potyamaz@gmail.com
}

\begin{abstract}
Resumo: Esta é uma reflexão que, aproveitando-se do ensejo comemorativo dos oitenta anos do Serviço Social no Brasil, faz um retrospecto da performance desta profissão na ordem burguesa, partindo dos países capitalistas que lhes serviram de berço. Esse périplo, no entanto, pretendeu realçar um denominador comum no Serviço Social mundializado, que é a sua propensão a remar, em qualquer contexto, contra os ditames do sistema que o engendrou. E com essa tendência - que não é unânime, mas historicamente persistente - ele tem sido um profícuo "ponto fora da curva" das profissões sucumbentes ao conservadorismo.
\end{abstract}

Palavras-chave: Serviço Social. Capitalismo. Conservadorismo. Insurgência. Cultura de oposição.
Abstract: This is a reflection that, taking advantage of the commemorative occasion of the eighty years of Social Work in Brazil, does a retrospect of the performance of this profession, in the bourgeois order, starting with the capitalist countries that served as its birthplace. This tour, however, intended to highlight a common denominator in the globalized Social Work, which is its tendency to row, in any context, against the system dictates that engendered it. And with this trend - which is not unanimous, but historically persistent - it has been a fruitful "point off the curve" of the rendered professions to conservatism.

Keywords: Social Work. Capitalism. Conservatism. Insurgency. Oppositional culture.

\section{Introdução}

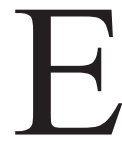

sta é uma reflexão desenvolvida a propósito dos oitenta anos do Serviço Social no Brasil. Nela reside uma forma particular de ver e pensar essa atividade que, no âmbito internacional, ganhou status de profissão, sob a égide do capitalismo industrial, mas nunca foi unanimemente obediente aos ditames de seu criador. Trata-se, a meu ver, de uma experiência que não surtiu completamente os efeitos desejados pelo sistema que a engendrou, funcionando como uma 
espécie de enfant terrible $e^{1}$ entre as práticas criadas para legitimá-lo. O que a levou a ser assim não é matéria destas elucubrações. Aproveitando o momento especial que permitiu a espontaneidade desta comunicação, importa aqui ressaltar um aspecto da história do Serviço Social além-fronteiras: o cultivo, no seu interior, de uma cultura de oposição ao conservadorismo, que não obstante minoritária, tem conseguido persistir no tempo e manter viva a disposição de fazer frente ao radicalismo burguês. E é essa disposição que tem caracterizado a invulgar relação de ambivalência do Serviço Social com a lógica capitalista, fazendo-o viver, constantemente, entre o fogo cruzado de concepções divergentes.

A apreensão dessa cultura de oposição exige um retrospecto da relação de ambivalência mencionada. Para tanto, julga-se necessário relembrar que o Serviço Social não nasceu no Brasil, mas sim nos países capitalistas centrais, que, por sua vez, mantiveram ascendência sobre os seus congêneres, posteriormente criados no chamado Terceiro Mundo; e também porque não há e nunca houve conformidade de pensamento e ação entre os assistentes sociais nem postura unívoca em relação aos projetos e pautas profissionais construídos em diferentes lugares e épocas.

Isso quer dizer que o Serviço Social, assim como as problemáticas e tarefas que lhes são afetas, pode e deve ser considerado um processo, e não um estado de coisa, natural, nem uma engenharia social requerida para ajustar desequilíbrios funcionais no sistema. E por ser um processo, é histórico e relacional, caracterizado por movimentos e contramovimentos, tendências e contratendências, e contradições perfeitamente cabíveis, por serem inerentes à dinâmica da vida real.

Contudo, a despeito dessas características e do fato de o Serviço Social ter se internacionalizado a ponto de atualmente existir em quase todas as partes do mundo, o que chama a atenção é o predomínio de seu perfil pragmático e conservador, embora contestado. E não poderia ser de outra forma, haja vista que as organizações europeias e norte-americanas, que difundiram e implantaram o Serviço Social para além de seus territórios, ou eram religiosas (católicas), com motivações catequizadoras, ou vinculadas à Organização das Nações Unidas (ONU), com propósitos domesticadores. Foi o caso do Fundo das Nações Unidas para a Infância (Unicef), cujos programas de cooperação e assistência técnica implantados no

1. Aqui entendido como um sujeito, individual ou coletivo, que, em um conjunto composto por diferentes atores, destaca-se por seu espírito inquieto e transgressor da ordem dominante. 
Terceiro Mundo incluíam a missão de formar assistentes sociais nativos por meio de ensinamentos produzidos na sede do imperialismo (Mindgley, 1997).

Eis por que o conservadorismo burguês constitui a matriz pioneira da visão de mundo dominante no Serviço Social desde os fins do século XIX; uma visão que se consolidou com os intentos de profissionalizá-lo e conferir-lhe cientificidade positivista, sob a direção da Charity Organization Society (COS — Sociedade de Organização da Caridade), criada inicialmente na Europa e, depois, nos Estados Unidos, para, segundo Rimlinger (1971), dar respaldo à concepção liberal de que o livre mercado - e não o Estado - era o principal agente de combate à pobreza. Afinal, estava implícito nessa ideologia que o pobre era o causador de sua própria situação de penúria e que a única forma de reabilitá-lo seria ajudá-lo a se autoajudar mediante o trabalho assalariado. Além disso, a COS apostava na ação do voluntariado para compensar a ausência do Estado junto aos casos mais agudos de empobrecimento, "cabendo aos voluntários, não apenas satisfazer necessidades extremas de pessoas sem condições de trabalhar, mas também educá-las" (Pereira-Pereira, 2011, p. 82). E educar, por essa perspectiva, tornou-se sinônimo de adestramento, funcional à ordem dominante e à ampliação do raio de influência dessa ordem, sem qualquer interesse de prover o Serviço Social de refinamentos teóricos, metodológicos e interventivos.

Isso explica por que os assistentes sociais de vários países europeus não possuíam curso superior; e onde escolas de nível universitário foram implantadas, como nos Estados Unidos, a intenção de dotar o exercício profissional de postura "científica" tomava de empréstimo procedimentos da medicina ou da psicanálise, como se as demandas sociais dirigidas aos profissionais requeressem tratos terapêuticos ou possuíssem cunho psíquico. Essa prática verificou-se, com notável recorrência, nos atendimentos de casos individuais ou pessoalizados, bem como nos trabalhos sociais com pequenos grupos. No entanto, até os programas de desenvolvimento de comunidade, que, a partir da década de 1930, se vincularam aos esforços de recuperação econômica no contexto da crise capitalista dos anos 1929-1933, assumiram características terapêuticas junto a desempregados e a outras vítimas da depressão e recessão econômicas que abalaram o capitalismo. Assim, embora o Serviço Social profissional tenha nascido, segundo Ander-Egg et al. (1975), sob a influência da sociologia aplicada norte-americana, de clara inclinação reformista e corretora de disfunções sociais, ele logo assumiu caráter psicologista dada à excepcional importância adquirida pela psicanálise nos Estados Unidos dos anos 1920. 
A obra de Mary Richmond, considerada pioneira do Serviço Social profissionalizado, é prova dessa tendência. Seu livro Social diagnosis, publicado em 1917 (apud Ander-Egg et al.), constituiu um guia metodológico inspirado em procedimentos investigativos adotados pela medicina, mas voltado para o conhecimento da situação social do "cliente" e da sua personalidade. A ênfase desse tipo de cientificidade recaiu no como fazer um bom diagnóstico para agir no sentido de resolver, junto com o atendido, o problema apresentado por ele e a ele circunscrito. Essa forma de investigação e de intervenção, referenciada nos protocolos médicos e psicológicos, contribuiu para que o Serviço Social funcionasse, durante muito tempo, como "olhos prolongados e braços estendidos" (Ander-Egg et al., 1975, p. 194) da medicina e, posteriormente, do Judiciário - duas áreas de conhecimento conservadoras que galgaram posições de destaque na opinião pública e transformaram o Serviço Social em auxiliar técnico-instrumental. Tal forma de subordinação do Serviço Social foi mais evidente na América Latina e, em particular, no Brasil.

Com o advento do Estado Social (Welfare State) - gestado desde finais do século XIX, no contexto europeu, e institucionalizado no segundo pós-guerra, em meio ao avanço tecnológico e à intensificação da exploração do trabalho assalariado pelo capital —, os Estados nacionais requisitaram pessoal técnico para intermediar conflitos de classe e desigualdades sociais. Para vários analistas, o Welfare State, que investiu maciçamente em ciência e tecnologia, bem como induziu o surgimento de várias profissões de conteúdo social, desejava salvar o capitalismo de suas crises endógenas (flutuações cíclicas, depressões, recessões) e de ameaças externas, como o avanço do nazismo e do socialismo. Eis por que, de par com o Serviço Social, outras áreas de conhecimento e ação, guiadas pelo paradigma funcionalista, valorizador do status quo, como a teoria da decisão, a cibernética, a pesquisa operacional, instituíram e se institucionalizaram (Gouldner, 1970). E isso se fazia mais necessário quanto mais imperiosa se tornava a intervenção estatal na economia e na sociedade por meio de legislações e políticas garantidoras de direitos conquistados pelos movimentos trabalhistas. Às profissões, portanto, caberia responder às exigências requeridas por esse momento de revisão estratégica do capitalismo desregulado, regido pelo princípio do laissez-faire, e funcionar como mecanismos derivados de uma cultura utilitária, identificada com o trabalho, cuja principal função era a de reinserir e controlar nessa cultura pessoas consideradas "inúteis". Por isso a transição para uma sociedade regulada pelo Estado social significava, conforme Gouldner (1970, p. 78), 
não apenas a passagem de um padrão de utilidade individual para outro de utilidade coletiva; mas também uma maior intervenção do Estado no desenvolvimento e administração da maneira de dispor dos "inúteis". [...]. Em certa medida, o crescimento mesmo do Estado social significa que o problema chegou a ser tão grande e complexo que já não pode ser possível deixá-lo sob o controle informal do mercado e outras instituições tradicionais. Cada vez mais a estratégia do Estado social [exige profissionalização] [...] consiste em transformar os enfermos, os desviados e os sem ofício em "cidadãos" inúteis para reintegrá-los à "sociedade" só depois de períodos de hospitalização, tratamento, assessoramento, educação ou reeducação. A insistência no remodelamento das pessoas é o que distingue as estratégias de diferenciação do Estado social das que tendiam a ocupar-se dos inúteis, sobretudo vigiando-os, excluindo-os e isolando-os da sociedade. (Tradução nossa)

\section{Reações à cultura utilitária integradora do Estado social e sua influência no Serviço Social}

Se partirmos do suposto esboçado na Introdução, de que todo processo social e político encerra contradições, tanto o Serviço Social quanto as políticas sociais com as quais aquele se articula configuraram-se também como espaços transitados por sujeitos contrários à utilitária cultura burguesa. Isso, sem dúvida, teve a ver com o surgimento, depois da Segunda Guerra Mundial, no lócus privilegiado do "paradigma pecuniário da utilidade"2 (Gouldner, 1970, p. 76) — os Estados Unidos da América do Norte — , de duas principais reações a esse paradigma.

A primeira, denominada por Gouldner de "revolta psicodélica", visou não apenas a sociedade capitalista em seu sentido geral, mas especialmente a capitalista industrial. Tal revolta constituiu, em essência, uma nova onda de antigas contestações

2. Trata-se, na formulação de Gouldner, de um paradigma cujo significado fundamental assenta-se na utilidade prática de pessoas e coisas, medidas pela sua capacidade de produzir lucro ou riqueza. Assim, o trabalho e a ocupação só têm valor se forem definidos como "empregos lucrativos", no sentido pecuniário. Em contraposição, a desocupação é um sinal de fracasso, e a recusa a assumir trabalho remunerado constitui grave ofensa moral, que indica degradação de caráter. De modo equivalente, a riqueza e o lucro tornam-se a base da "estima" social. Não importa o que a pessoa faça, mas sim quanto ganha e o que pode comprar. Por essa perspectiva, fazer algo que enterneça a alma, como poesia, música, arte em geral, ou cultivar valores como a bondade, a coragem, a cortesia, serão coisas marginais que não contribuem para a rotina lucrativa da produção industrial nem para vida pública (p. 76-77). 
sociais, iniciadas no século XVIII e cristalizadas no movimento romântico do século XIX. No século XX, tal onda notabilizou-se pela defesa de posturas conscientemente "desviadas" dos valores prático-utilitários, centrados na alienante posse do dinheiro e na servidão voluntária ao trabalho assalariado. Sua aparição, sob diferentes tipos - dentre os quais os beats e os hippies - , constituiu um sintoma de insatisfações renovadas com todas as variantes da sociedade industrial, entre as quais ressaltam: a forma mercantil de industrialização; o culto alienado do dinheiro; as atividades empresariais e laborais voltadas para o lucro e a cobiça; a luta pela obtenção de status como mérito competitivo; a busca do poder econômico e a realização de atividades rotineiras voltadas para esse fim; a inibição da expressão, da criatividade e de impulsos individuais e sociais dissidentes. Enfim, representou uma contracultura que, sob o nome de psicodélica, rechaçava o valor da utilidade conformista, contrapondo-lhe a ousadia de viver em desacordo com os seus preceitos. Afinal, ser psicodélico era abrir e projetar a alma para fora de uma vida amarrada a valores materiais.

As possíveis influências desse movimento sobre a emergência de posturas não conservadoras no âmbito do Serviço Social ainda estão por ser estudadas, assim como a qualidade e a densidade crítica das mesmas. Mas é fato inconteste que, dentro dos limites de sua capacidade de persuasão, elas existiram e marcaram presença internacional como contraponto aos valores burgueses. Se, posteriormente, esse movimento sucumbiu ao sistema criticado, como alertam alguns, ou serviu de compensação à difícil experiência de participar das desumanas engrenagens do capitalismo, como afirmam outros; ou, ainda, possuía matizes religiosos e "românticos" (no sentido depreciativo da palavra) e resvalou para o exotismo, a vulgaridade, o uso de drogas, a rejeição ao estudo e ao trabalho formais, isso não elide a sua revolta contra o poder estrutural do capital. Até porque o capitalismo - mesmo na sua fase mais opulenta e perdulária — nunca se revelou um deus ex machina, ${ }^{3}$ dotado de condição mágica para solucionar os impasses por ele mesmo criados. Logo, a referida revolta, embasada nesse reconhecimento, demonstrou ser possível plantar no sistema do capital contraposições a ele, negando-lhe legitimação.

3. Literalmente esta expressão quer dizer "deus surgido das máquinas" ou deus mecânico. Mas o sentido aqui utilizado toma de empréstimo o seu uso não literal que designa um sujeito com capacidade de, unilateralmente, resolver impasses cruciais. 
Quanto à segunda reação, também forjada nos Estados Unidos, pode-se dizer que possui maior relação com o Serviço Social; e tudo indica que seus integrantes não se mantiveram alheios e ao largo das influências do movimento anterior, já que, conforme Gouldner (1970, p. 81), algo de novo foi despertado pela contracultura psicodélica: não só os "párias e pobres" nem apenas os "guetos do lumpenproletariat" dela participaram, mas "até membros respeitáveis de profissões cívicas passaram a 'agitar-se' como círculos artísticos boêmios". E isso revela que o rechaço da cultura utilitária, por parte das classes subalternas, não foi mera consequência do "fracasso" dessas classes em se adaptar a um mundo superior a elas, como muitos dão a entender.

A segunda reação, portanto, engendrou uma corrente de pensamento econômico, também pouco estudada, denominada "economia política radical" (radical political economics). Tal denominação foi usada pela primeira vez "nos finais dos anos 1960 por economistas progressistas estadunidenses, que formaram a Union for Radical Economics/Urpe, e editaram a revista Review of Radical Political Economics/RRPE"' (Sutcliffe, 1998, p. 9-10), para divulgar suas produções. Com essa nomenclatura, eles não visavam apenas criar uma etiqueta distintiva no campo socialista, mas, conforme Barceló (1998), queriam vinculá-la a uma organização e a um veículo de comunicação específicos - a Urpe e a RRPE estadunidenses também batizados de "radicais". Por outro lado, o resgate do termo liberal clássico "economia política" - já em desuso, nos anos 1960, devido à conversão da economia a uma espécie de ciência exata, divorciada da política e da vida social pretendia reinserir esse ramo de saber no contexto das ciências humanas. O objetivo declarado dos economistas políticos radicais, no qual transparece o significado de sua radicalidade em terras liberais, era o de mostrar

a conexão inerente entre as múltiplas opressões que rodeavam a teoria econômica ensinada nas escolas. Eles [os economistas políticos radicais] apontavam, sobretudo, para os limites do reformismo liberal. Enfatizavam que os programas contra a pobreza não poderiam ter sucesso por causa dos conflitos de classe característicos do capitalismo. Algo similar ocorria com o racismo, o sexismo, o consumismo, a destruição do meio ambiente, o militarismo e o imperialismo. Estas análises ressaltavam também a importância dos novos movimentos sociais progressistas e da ajuda a sua formação e consolidação. [...] Achavam que esses movimentos não estavam bem representados nem pelos partidos nem pelos sindicatos tradicionais. Desse modo, a economia política radical poderia apoiá-los como um enfoque novo. [...] As diferentes opressões 
poderiam ser concebidas como manifestação de causa única e, ao possuir as mesmas raízes, permitia considerar uma luta política de envergadura com base na organização de uma coalizão que integraria todas as frações que, juntas, avançariam com mais força. (Barceló, 1998, p. 28; tradução nossa)

De onde se conclui que ser radical, por essa ótica, é não ser liberal ou conservador e muito menos um produto da fusão de ambos; mas também é não ser um revolucionário nos moldes marxianos. Seu laivo revoltoso reside na sua determinação de remar contra a corrente em uma sociedade tradicionalmente liberal, angariando simpatias ideológicas e sensibilidades analíticas diversas. Entre os seus integrantes figuram libertários, marxistas, social-democratas e humanistas de diferentes teores, todos empenhados na crítica socialista da sociedade e das instituições capitalistas (Galper, 1986). Sua história, que perdura até hoje, com percalços, é válida pelo menos para confirmar que o modo capitalista de produção nunca esteve livre de contestações em seu próprio âmbito.

Foi simultaneamente a esse movimento contestador que o Serviço Social profissional tornou explícita a sua relação de ambivalência com os princípios e valores utilitaristas burgueses, ao também chamar para si a designação de "radical" (Ferguson, 2001, p. 40). E assim surgiu, nos fins dos anos 1960, nos Estados Unidos, a primeira vertente alternativa ao conservadorismo da profissão, que passou a denominar-se Serviço Social Radical e a espraiar-se para outros países capitalistas centrais, como a Grã-Bretanha e o Canadá, seguidos da Austrália. Essa postura teve como determinantes os mesmos acontecimentos estruturais e históricos que deram origem à economia política radical estadunidense, a saber:

a) Declínio, no final no final dos anos 1970, do crescimento econômico do segundo pós-guerra.

b) Redescoberta da pobreza por pesquisadores que passaram a discordar da percepção psicossocial de que no pobre residiam as razões de sua privação material.

c) Realização de importantes estudos sobre a percepção dos usuários a respeito dos atendimentos que lhes eram prestados pelo Serviço Social (Howe, 1987).

d) Movimento global de resistência à guerra fratricida dos Estados Unidos no Vietnã. 
e) Eclosão de novos movimentos sociais: feminista, ecológico, antirracista, estudantil de 1968, que apoiou, com veemência, as rebeliões da "Primavera de Praga", em defesa da democratização da Tchecoslováquia; e a monumental greve dos trabalhadores franceses, também em 1968, que obrigou o presidente da república, general Charles de Gaulle, a se refugiar em uma base militar na Alemanha. Esses movimentos, pelo seu caráter radicalmente antitético ao status quo, transformaram o período compreendido entre metade dos anos 1960 e metade dos anos 1970, na "década mais radical da história mundial" a partir do final da Primeira Grande Guerra (Ferguson, 2011, p. 41). Seu lema era: "Seja realista. Exija o impossível".

f) Crise capitalista dos fins dos anos 1970, que completou o cenário de conturbações sociais e ensejou tanto nas Ciências Sociais quanto no Serviço Social um redirecionamento da visão conservadora de muitas cabeças pensantes. No Serviço Social ficou claro, para os segmentos profissionais mais críticos, que, em vez dos alegados desajustes pessoais e psíquicos, as demandas e necessidades postas aos assistentes sociais tinham raízes estruturais reproduzidas por relações de dominação de classe, o que exigia luta coletiva por mudança.

Contudo, nos anos 1980, esta postura radical do Serviço Social no Primeiro Mundo - que também contou com uma nova legislação favorável à reorganização da prática profissional e à criação de equipes mais amplas e combativas (Ferguson, 2011) - entrou em declínio. A desencadear essa queda, destacam-se, principalmente: a ascensão do neoliberalismo em escala global e a virada para a direita da maioria dos governos e de parcelas majoritárias da sociedade, incluindo círculos intelectuais, políticos e de informação. As políticas públicas, entre elas as sociais, com as quais o Serviço Social mantém contínua interlocução, tornaram-se reféns do ideário neoliberal; e este, associado à mentalidade conservadora, compôs uma doutrina híbrida ultraliberal/conservadora retrógrada, denominada "nova direita", que se mostrou francamente contrária a tudo o que é social, público, universal e desmercadorizado. Consequentemente, tal doutrina passou a defender tudo o que é individual, privado, focalizado, seletivo e mercadorizado. Para a "nova direita", portanto:

a) O Estado social deveria ser antissocial, ou, no máximo residual e, por conseguinte, focalizado tanto no público-alvo quanto nos recursos a serem 
despendidos. Daí decorre o desprezo pelos pobres e o recrudescimento dos preceitos da doutrina do darwinismo social, que valoriza o mais forte e condena à extinção o mais fraco.

b) A cidadania, que antes tinha um escopo ampliado, deveria se restringir aos direitos individuais, porque os sociais foram negados como direitos genuínos. Contra os direitos sociais, que deveriam ser concretizados por políticas sociais, instituiu-se o mérito referenciado na competição e na conquista por parte de cada um do poder de assumir o seu próprio bem-estar. Consequentemente, o trabalho assalariado, produtor de mais-valia, tornou-se o meio mais digno de obtenção desse poder, desbancando qualquer pretensão pública de proteção social como direito.

c) A democracia perdeu a sua dimensão participativa para ser identificada apenas como um regime político representativo reduzido ao ato de votar, exercido por eleitores geralmente apáticos e mobilizados de tempos em tempos.

d) As necessidades sociais foram confundidas com preferências, desejos e sonhos de consumo e, portanto, perderam reconhecimento ontológico. Em seu lugar, prevalecem demandas e compulsões consumistas individualizadas e subjetivas, que desobrigam o Estado de seu atendimento e incumbem ao mercado essa tarefa. Nesse contexto, o Serviço Social tornou-se uma profissão non grata por criar empecilhos à difusão consensual da ideologia da autossustentabilidade mediante o trabalho assalariado ou remunerado, cada vez mais flexível, incerto e desprotegido. E, nesse contexto, tanto o Serviço Social quanto a política social só adquirem serventia se tornarem-se funcionais aos objetivos de reprodução ampliada do capital. Esse fato tem sido um sério obstáculo ao desempenho de um Serviço Social guiado por um projeto que vislumbre a construção de uma sociabilidade anticapitalista.

Tendo em mente esse desafio, cumpre abordar as particularidades da tensão entre conservadorismo e resistência do Serviço Social latino-americano e brasileiro, o qual, à semelhança de seus congêneres no Terceiro Mundo, sofreu influências das matrizes europeias e norte-americanas, porém sem sucumbir a elas. 


\section{Serviço Social latino-americano/brasileiro e suas insubordinações possíveis}

Guardadas as devidas proporções e considerando a dinâmica particular do capitalismo na América Latina, pode-se dizer que também nesta região, da qual o Brasil faz parte, instituiu-se, nos anos 1960, uma espécie de Serviço Social "radical". Este se denominou "reconceituado" e também se colocou como alternativa ao modelo conservador herdado principalmente dos Estados Unidos. Contudo, isso não quer dizer que o Serviço Social latino-americano e brasileiro seja um desdobramento ou simples reflexo de experiências conservadoras ou revolucionárias primeiro-mundistas. Pelo contrário. Os fatores estruturais que propiciaram o advento do Serviço Social radical no Primeiro Mundo, e que aqui exerceram influência, foram entremeados por "prefigurações" ou "protoformas" de insurgências peculiares que, conforme Manrique Castro (1984, p. 21), já vinham sendo gestadas internamente e deram origem a uma específica insubordinação do Serviço Social nestas paragens. Entre os fatores regionais e locais que contribuíram para essa mudança, destacam-se, segundo Palma (1977):

a) Um crescente nacionalismo de fundo antinorte-americano, que se alastrou pelo continente latino-americano, no rastro do aumento das expectativas por transformações nas tradicionais relações de subordinação da região com os Estados Unidos. O relaxamento da beligerância frontal entre Ocidente e Oriente dos tempos de guerra e a geração de um novo ciclo de atuação capitalista, voltado para a paz, tornou possível a crítica ao sistema dominante e a sua rejeição.

b) A propagação, na região, de um marxismo humanista, mormente entre os círculos intelectuais e políticos, que passaram a considerá-lo a ferramenta mais adequada para o conhecimento da realidade regional, visando a sua transformação.

c) O triunfo da Revolução Cubana, em 1958-1959, que pôs "em xeque as velhas estruturas capitalistas e se apresentou, no continente, como uma possibilidade de desenvolvimento alternativo" (Palma, 1977, p. 21), de filiação socialista, ao que existia.

d) A difusão, na região, de um clima de otimismo despertado pela Revolução Cubana e pelo ideário anticapitalista, criando, no Brasil, anseios por reformas de base que questionavam a estrutura de dominação econômica, 
política e social prevalecente, responsável pelo subdesenvolvimento nacional. De par com essas reformas — das quais faziam parte a agrária (o carro-chefe), a urbana, a fiscal, a administrativa, a bancária, a universitária - emanavam pleitos pela extensão do voto aos analfabetos, por mais ampla intervenção do Estado na economia e por maior regulamentação de remessas de lucros para o exterior.

Ou seja, imperou, nos anos 1960, no continente latino-americano, uma espécie de euforia por mudanças, representada pela disposição não só política, mas também cultural, de renovação, que lembram os chamados movimentos rebeldes e de contracultura dessa década, dos países capitalistas centrais, entre os quais os psicodélicos.

Para ter-se uma ideia da força dessa investida supraestrutural, que de certa forma repercutiu no desencadeamento do processo de reconceituação do Serviço Social na América Latina e no Brasil, vale indicar, seguindo as pegadas de Palma (1977), dois processos particulares de mudança: o da Igreja Católica, com a qual o Serviço Social mantinha histórica vinculação; e o das universidades, de onde brotaram ideias inovadoras que propunham não só a revisão das pautas pedagógicas, mas também do sentido da formação e de sua função social.

No tocante à Igreja, merecem menção os movimentos e obras de renovação, em grande parte instigados por mudanças verificadas na cúpula do catolicismo, cujo maior exemplo foi a postura não convencional do papa João XXIII de procurar aproximar a doutrina católica do mundo moderno. Por meio da convocação, em 1964, do Concílio Vaticano II, o referido papa, que recebeu em vários momentos a pecha de esquerdista, pregava a liberdade religiosa e o ecumenismo, além da defesa de uma nova ordem mundial socialmente mais justa. $\mathrm{Na}$ esteira dessa tendência surgiram na América Latina e no Brasil, principalmente nos anos 1970-80, as Comunidades Eclesiais de Base (Cebs), pautadas por uma teologia da libertação, que priorizava os oprimidos pela miséria e pelo poder ditatorial que assolava o continente.

Quanto às universidades, é digno de nota o impulso mudancista que, por volta de 1967, colocou o movimento estudantil na liderança das pressões coletivas por melhor qualidade de ensino; maior correspondência entre teoria, empiria e prática profissional; e mais estreita relação entre ensino, pesquisa e a realidade regional. Foram esses mesmos estudantes, entre os quais vários de Serviço Social, que protagonizaram gestões com vistas à alteração das estruturas conservadoras 
dos estabelecimentos de ensino e pressionaram por atualização do corpo docente e dos conteúdos curriculares. Estabelecendo interlocuções com as ciências humanas, que também se atualizavam, o Serviço Social sentiu necessidade de transcender o empirismo mimético a que se via restrito, para buscar explicações fundamentadas em teorias informadas pela realidade e mediadas por um método que, no dizer de Paula (1992), "tem que se mover, tem que acompanhar" (p. 29) as sinuosidades e movimentos do mundo real, que são dialéticos; um método que não seja diferente de seu objeto e que, junto com o sujeito, percorra o mesmo caminho, tornando-se dialético.

Disso resultou o propósito, nem sempre claro e bem definido, mas verdadeiro, de rompimento epistemológico com paradigmas funcionais à reprodução da ordem burguesa, o que passou a requerer importantes mudanças paradigmáticas, conceituais e na formação escolar. Com efeito,

durante décadas este Serviço Social havia agido de forma funcional ao sistema dominante, havia amortecido o conflito, havia tratado dos sintomas sem ir às raízes da enfermidade e, no entanto, essa situação objetivamente insatisfatória não tinha sido percebida como tal na consciência dos atores que nela intervinham. (Palma, 1977, p. 24; tradução nossa)

Em vista desse quadro, e com o objetivo de formar profissionais dotados de consciência crítica, que remete aos preceitos pedagógicos libertadores do educador Paulo Freire - a meu ver, outra importante fonte de inspiração do processo de reconceituação do Serviço Social brasileiro - e comprometidos com mudanças que revertessem as condições desumanas de vida e de trabalho da maioria, foram exigidas das escolas de Serviço Social providências como estas:

a) Adoção do paradigma marxista, por oposição ao funcionalista.

b) Busca de um referencial teórico mais amplo, baseado nas ciências sociais.

c) Uso da dialética materialista histórica como lógica e método de investigação e ação.

d) Priorização do trabalho social em comunidades ou coletividades, em contraposição às abordagens individuais ou grupais.

e) Valorização da pesquisa e da produção do conhecimento pelos assistentes sociais (Netto, 2007). 
Foi nesse contexto que se delineou, no Brasil, o Projeto Ético e Político do Serviço Social, que assumiu um explícito comprometimento com os pleitos sociais da classe trabalhadora e ganhou hegemonia no debate acadêmico dos anos 1990 .

Coroando os esforços pioneiros de reconceituação do Serviço Social na perspectiva crítica, empreendidos nos anos 1960, esse projeto profissional foi encampado não apenas pela área acadêmica, coordenada pela Associação Brasileira de Ensino e Pesquisa em Serviço Social (Abepss), mas também por um complexo aparato institucional composto de lei federal, regulamentadora da profissão; Código de Ética cujos postulados e normas são de cumprimento obrigatório, embora não coativos; e de um conjunto de órgãos fiscalizadores, constituído de conselhos - federal e regionais. Isso sem falar da organização dos estudantes, em âmbito nacional, regional e local, em que a perspectiva crítica e progressista da profissão é cultivada e defendida.

\section{Palavras finais}

Entrementes, todos os valores e princípios projetados e respaldados institucionalmente pelo contemporâneo Serviço Social brasileiro não ganharam unanimidade no seio da profissão nem se concretizaram tal como desejado. O Projeto Ético-Político é uma construção em processamento, inspiradora de debates que podem ser salutares pela possibilidade de suscitar resistências democráticas e atualizações consistentes da profissão. Sua hegemonia no campo acadêmico não significa eliminação da pluralidade de visões de mundo e de paradigmas que se colocam, competitivamente, no cenário brasileiro e mundial. E nem é essa a sua expectativa, especialmente no que diz respeito à pluralidade. O que é inaceitável é o poder despótico da ideologia do capital contra a democracia substantiva em curso.

Tal como aconteceu com o Serviço Social radical norte-americano, que, segundo Ferguson (2011), ainda não desistiu de se fazer valer, o Projeto Ético-Político brasileiro tem enfrentado oposições sem se afastar de seus pressupostos; isto é, tem enfrentado perspectivas que lhes são contrárias e que, sutil ou abertamente, condenam a sua ênfase nas classes sociais e na realidade objetiva, assim como o seu tributo a uma teoria crítica, dialeticamente totalizante e abrangente. É o caso da perspectiva pós-moderna, que aposta no subjetivismo, no relativismo, no pragmatismo, nas teorias de pequeno alcance, no sincretismo profissional, na focalização 
das diferenças, das identidades, das individualidades, as quais renegam o universalismo por entendê-lo massificador e indiferenciado. Não admira que essa visão de mundo pós-moderna tenha se dado bem com as estratégias neoliberais, defensoras da participação do mercado na área social, da diminuição da intensidade protetora do Estado e da incorporação da lógica empresarial no processo de gestão das políticas sociais, as quais requerem: privatização dos serviços públicos, seletividade fiscal favorável aos ricos, desregulamentação financeira, terceirização, contratos por tempo determinado, medidas quantificáveis de desempenho e avaliação, que têm impingido sofrimento e frustração aos profissionais (Ferguson, 2011).

Enquanto isso, as desigualdades sociais se multiplicam em âmbito mundial, exigindo a reiteração de um Serviço Social crítico incansavelmente baseado em valores inegociáveis, inscritos em seus projetos de superação da ordem burguesa. Esse é um chamamento ao qual a parcela progressista do Serviço Social brasileiro tem respondido - mais como um enfant terrible do que como um "Dom Quixote" - com brio profissional, se comparada à sucumbência servil e antiética de várias outras profissões aos cantos traiçoeiros da sereia capitalista dos tempos correntes.

Como se sabe, a história não possui uma direção única e, portanto, nunca se coloca como fatalidade. Construí-la e orientá-la em direções democráticas é tarefa possível, embora não gratuita e muito menos mágica. É essa consciência que anima e estimula a continuidade do empenho profissional por um Serviço Social responsivo aos legítimos reclamos sociais que lhes são dirigidos. Mas também é essa consciência que vai exigir, dos profissionais, compromissos teóricos, políticos e éticos, que não se recusem a produzir saberes por iniciativa própria; a pensar e a repensar o Serviço Social na sua complexidade; a confundir a linguagem dos direitos com a dos negócios e a deslegitimar falsas necessidades irresponsavelmente criadas pela lógica do consumo compulsivo. Significa, ademais, colocar como prioridade o combate à concentração de poder e riqueza, porque, mais do que a pobreza e a desigualdade social em si, é esse o determinante das iniquidades sociais que barbarizam a sociedade brasileira.

Para tanto, o Serviço Social tem que se reconhecer também como um ramo de conhecimento (Pereira-Pereira, 2008), que se estuda e transmite nas universidades e se alimenta e se renova por meio de pesquisas de qualidade e de produção coletiva de um saber que lhe é particular. Isso exige que o assistente social seja ao mesmo tempo estudioso e crítico. Crítico impiedoso, parafraseando Marx, em dois sentidos principais: a) de não aceitar nada sem exame prévio e minucioso, para ter 
certeza e segurança do que está falando e defendendo; b) de não temer os resultados de sua crítica e nem tampouco os conflitos que dela advirão.

Essas são as coordenadas pelas quais um Serviço Social que se pretenda inquieto, crítico e democrático, tem de se pautar para não sucumbir, como fizeram várias profissões, às novidades de um discurso e de uma prática neoliberais sem compromissos com a verdade.

\section{Recebido em 4/5/2016 a Aprovado em 13/6/2016}

\section{Referências bibliográficas}

ANDER-EGG, E. et al. Del ajuste a la transformación: apuntes para una historia del Trabajo Social. Buenos Aires: Editorial Ecro, 1975.

BARCELÓ, A. Economía politica radical. Barcelona: Editorial Sintesis, 1998.

FERGUSON, I. Um outro Serviço Social é possível: reivindicando a tradição radical. Em Pauta, revista da Faculdade de Serviço Social da Universidade do Estado do Rio de Janeiro, Rio de Janeiro, n. 27, jul. 2011.

GALPER, J. Política social e trabalho social. São Paulo: Cortez, 1986.

GOULDNER, A. La crisis de la sociología occidental. Buenos Aires: Amorrotu Editores, 1970.

HOWE, D. An introduction to social work theory. Inglaterra: Ashgate Publish Lilited; Estados Unidos: Adhgate Publish Company, 1987.

MANRIQUE CASTRO, M. História do Serviço Social na América Latina. São Paulo: Cortez, 1984.

MINDGLEY, J. Social welfare in global context. Londres: Sage Publications, 1997.

NETTO, J. P. Serviço Social na América latina. Em Pauta, revista da Faculdade de Serviço Social da Universidade do Estado do Rio de Janeiro, Rio de Janeiro, n. 19, 2007.

PALMA, D. La reconceptualización: una búsqueda en América Latina. Buenos Aires: Editorial Ecro, 1977. 
PAULA, J. A. de. A produção do conhecimento em Marx. Cadernos Abess, São Paulo, n. 5, 1992.

PEREIRA-PEREIRA, P. A. Natureza do Serviço Social: complexidade, contradição e multideterminação. O Social em Questão, Rio de Janeiro, n. 19, 2008.

. Política social: temas e questões. 3. ed. São Paulo: Cortez, 2011.

RIMLINGER, G. V. Welfare policy and industrialization in Europe, America and Russia. Nova York: John Willey \& Sons, Inc., 1971.

SUTCLIFFE, B. Apresentação. In: BARCELÓ, Alfons. Economía política radical. Barcelona: Editorial Sintesis, 1998. 